\title{
PERENCANAAN PERHITUNGAN AKNOP PADA DAERAH IRIGASI MRICAN SEBAGAI UPAYA PENINGKATAN KINERJA IRIGASI
}

\author{
Erna Tri Asmorowati ${ }^{1)}$, Diah Sarasanty ${ }^{1)}$ \\ 1) Progam Studi Teknik Sipil Fakultas Teknik Universitas Islam Majapahit \\ Jl. Raya Jabon - Km 07 Mojokerto, Jawa Timur
}

\begin{abstract}
Food security is one of the targets of the Sustainable Development Goals that must be achieved by 2030. One of the problems faced in achieving this target is the decrease in the function of irrigation infrastructure by $\pm 70 \%$, resulting in the reduced water supply to agricultural land. The purpose of this research is to recalculate the operational and maintenance needs of the Mrican Irrigation Area by the applicable regulations and the current conditions of the study area for the needs of the 2021 budget year.The research was conducted in the Mrican Irrigation Area with an area of 30,341 ha located in 3 districts, namely Kediri, Nganjuk and, Jombang. The result of optimization calculation of personnel for operational activities and maintenance of irrigation networks in the Mrican Irrigation Area is 577 people. The length of the carrier line is $366 \mathrm{~km}$ and the drainage is $248 \mathrm{~km}$ long. The number of waterworks as many as 966 units. The results of calculations and analyzes that have been carried out, it is found that the amount of the Operational and Maintenance Real Needs of Mrican Irrigation Area for the irrigation operational management component is Rp. $6,329,767,232$, the component of surface irrigation operation costs Rp. 31,490,208,724, and the maintenance component of the surface irrigation network is Rp. 22,685,844,371. The total cost of the Operational and Maintenance Real Needs of Mrican Irrigation Area is Rp. 60,505,820,327.
\end{abstract}

Key Words: food security, irrigation cost, mrican, operational irrigation, waterworks.

\section{PENDAHULUAN}

Salah satu pemanfaatan sumber daya air adalah pemanfaatan air untuk kegiatan irigasi dengan tujuan peningkatan ketahanan pangan. Dimana ketahanan pangan merupakan salah satu target Tujuan Pembangunan Berkelanjutan yang harus dicapai pada tahun 2030. Menurut Soekrasno (2019), kerusakan irigasi di Indonesia sampai tahun 2008 mencapai 22,5 $\%$. Hal ini disebabkan karena gangguan alam dan lemahnya operasi dan pemeliharaan. Sedangkan menurut Suswono (2012) dalam Puspitasari (2014), kerusakan irigasi di Indonesia mencapai 52\%, sehingga dibutuhkan dana sebesar 3 triliun rupiah untuk perbaikan sampai tahun 2014.

Penyebab lain kerusakan jaringan irigasi adalah minimnya anggaran dan tidak terserapnya anggaran secara maksimal (Puspitasari, 2014). Oleh karena itu, dibutuhkan suatu perhitungan angka kebutuhan nyata operasional dan pemeliharaan jaringan irigasi yang memperhitungkan secara rinci seluruh kebutuhan operasi dan pemeliharaan pada suatu daerah irigasi.

Daerah Irigasi (DI) Mrican merupakan salah satu Daerah Irigasi di Provinsi Jawa Timur yang berada dibawah kewenangan Balai Besar Wilayah Sungai Brantas. Berdasarkan Peraturan Menteri Pekerjaan Umum No 14/PRT/M/2015 tentang Kriteria dan Penetapan Status Daerah Irigasi, Daerah Irigasi
Mrican merupakan daerah irigasi lintas kabupaten/kota dengan luas daerah irigasi sebesar 30.341 Ha terbagi menjadi Mrican Kiri seluas 12.729 Ha dan Mrican Kanan seluas 17.612 Ha (Kementrian PUPR, 2015). Luasan tersebut tersebar pada 3 (tiga) kabupaten yaitu: Kabupaten Kediri, Kabupaten Nganjuk, dan Kabupaten Jombang. Kondisi daerah irigasi yang luas seperti ini membutuhkan tenaga, peralatan dan biaya yang tidak sedikit dalam operasi dan pemeliharaan jaringan irigasinya. Setiap tahun, kebutuhan biaya operasi dan pemeliharaan suatu daerah irigasi berubah sesuai dengan kondisi jaringan irigasi saat ini. Selain itu, perubahan biaya operasi dan pemeliharaan setiap tahun dipengaruhi oleh perubahan harga material, peralatan, dan upah/honor sesuai dengan keputusan pemerintah.

Berdasarkan petunjuk teknis, penyusunan Angka Kebutuhan Nyata Operasi dan Pemeliharaan Irigasi (AKNOP) dilakukan pada dua bagian yaitu AKNOP bendung dan AKNOP jaringan (Djuhartono, 2020). Pada Daerah Irigasi Mrican ini, hanya akan dilakukan perhitungan pada jaringan saja, karena bendung gerak Mrican dalam kewenangan Perum Jasa Tirta I. Perencanaan perhitungan AKNOP jaringan irigasi meliputi :

1) Perhitungan biaya manajemen pelaksanaan operasi dan pemeliharaan. 
2) Perhitungan biaya untuk kegiatan operasional jaringan irigasi permukaan.

3) Perhitungan biaya kegiatan pemeliharaan jaringan irigasi permukaan.

Tujuan dari penelitian ini adalah menghitung kembali kebutuhan angka kebutuhan nyata operasi dan pemeliharaan (AKNOP) daerah studi sesuai dengan ketentuan yang berlaku dan kondisi daerah studi saat ini untuk kebutuhan tahun anggaran 2021.

\section{METODOLOGI}

Lokasi penelitian berada di Daerah Irigasi Mrican dengan bangunan utama Bendung Gerak Mrican, dimana bendung gerak ini mempunyai dua pengambilan, yaitu:

1) Pengambilan kanan untuk mengairi Daerah Irigasi Mrican Kanan yang secara administrasi mengairi lahan yang berada di Kabupaten Kediri dan Kabupaten Jombang.

2) Pengambilan kiri untuk mengairi Daerah Irigasi Mrican Kiri dimana lahan yang diari masuk dalam wilayah administrasi Kabupaten Kediri dan Kabupaten Nganjuk.

Batas wilayah Daerah Irigasi Mrican adalah:

- Sebelah Utara : Kali Widas dan Brantas

- Sebelah Timur : Daerah Irigasi Siman

- Sebelah Selatan : Daerah Irigasi Siman

- Sebelah Barat : Kali Kedungsoko

Kebutuhan data yang digunakan dalam perhitungan AKNOP irigasi, meliputi:

1) Data primer: wawancara dengan kepala UPT dan P3GAI terkait kebutuhan operasi dan pemeliharaan.

2) Data sekunder:

a) Data inventarisasi saluran dan bangunan.

b) Data kegiatan pemantauan, evaluasi dan pelaporan.

c) Data standar biaya umum harga satuan standar barang dan jasa yang ditentukan oleh menteri keuangan dan pemerintah daerah.

d) Data struktur organisasi unit pengelola teknis dan jumlah personil operasi dan pemeliharaan daerah irigasi.

e) data inventaris kantor.

Berdasarkan data yang telah diperoleh, dilakukan perhitungan AKNOP irigasi dengan prosedur sebagai berikut (Djuhartono, 2020) :

1) Menentukan jenis kegiatan operasi dan pemeliharaan jaringan irigasi

2) Menentukan frekuensi dan menghitung volume masing-masing kegiatan operasi dan pemeliharaan jaringan irigasi

3) Menghitung harga satuan pekerjaan (HSP) masing-masing kegiatan operasi dan pemeliharaan jaringan irigasi
4) Menghitung angka kebutuhan nyata operasi dan pemeliharaan (AKNOP) jaringan irigasi, meliputi :

a) Melakukan optimalisasi personil daerah irigasi sesuai dengan Peraturan Menteri PUPR no 12/PRT/M/2015 (Kementrian PUPR, 2015).

- Kepala pengamat/UPTD:

$$
N_{U P T D}=\frac{A_{D I}}{A_{U P T}}
$$

- $\quad$ Staff Pengamat/UPTD:

$$
N_{\text {staff }}=5 \times N_{U P T D}
$$

- Kebutuhan Juru/Mantri:

$$
N_{\text {Juru }}=\frac{A_{D I}}{A_{\text {juru }}}
$$

- Kebutuhan Penjaga Pintu Air (PPA)

$$
N_{P P A}=\frac{N_{B g n}}{n_{P P A}}
$$

- Kebutuhan Pekarya :

$$
N_{\text {Pekarya }}=\frac{P_{\text {Sal }}}{P_{\text {pekarya }}}
$$

Dimana :

$\mathrm{N}_{U P T D}=$ kebutuhan jumlah pengamat (orang)

$\mathrm{A}_{\mathrm{DI}}=$ luas daerah irigasi

$\mathrm{A}_{\mathrm{UPT}}=$ luas penetapan wilayah kerja pengamat $(5000-7000 \mathrm{Ha}$ untuk satu orang pengamat)

$\mathrm{N}_{\text {staff }}=$ kebutuhan staff pengamat (orang)

$\mathrm{A}_{\text {juru }}=$ luas penetapan wilayah kerja juru ( $750-1500$ Ha untuk 1 orang juru )

$\mathrm{N}_{\mathrm{PPA}}=$ kebutuhan pengamat pintu air (orang)

$\mathrm{N}_{\text {Bgn }}=$ jumlah bangunan bagi-sadap/sadap (3 - 5 bangunan untuk 1 orang PPA)

$\mathrm{P}_{\mathrm{sal}}=$ panjang saluran daerah irigasi $(\mathrm{km})$

$\mathrm{P}_{\text {pekarya }}=$ panjang penetapan wilayah kerja ruas pekarya $(2-3 \mathrm{~km}$ untuk 1 orang pekarya)

b) Melakukan perhitungan biaya manajemen pelaksanaan operasi dan pemeliharaan, meliputi:

- Gaji/honor/upah

- Operasional kantor

- Sarana pelaksanaan operasi dan pemeliharaan

- Perlengkapan kerja

- Peralatan kerja

- Kegiatan pembentukan/update data

- Pendukung operasi dan pemeliharaan

- Pembinaan operasi dan pemeliharaan P3A/GP3A/IP3A

c) Melakukan perhitungan biaya operasi irigasi permukaan, meliputi:

- Perencanaan tahunan

- Pelaksanaan operasi jaringan irigasi

- Pemanfaatan sumber lain

- Monitoring dan evaluasi

d) Melakukan perhitungan biaya pemeliharaan jaringan irigasi permukaan, meliputi :

- Inventarisasi jaringan

- Perencanaan pemeliharaan jaringan irigasi 


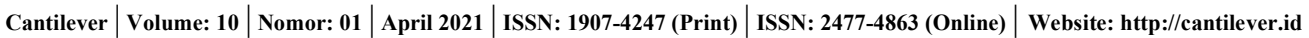

Erna Tri Asmorowati dan Diah Sarasanty | Perencanaan Perhitungan Aknop Pada Daerah Irigasi Mrican sebagai Upaya Peningkatan Kinerja Irigasi

- Pemeliharaan rutin bersifat perawatan

- Pemeliharaan rutin bersifat perbaikan ringan

- Pemeliharaan berkala bersifat perawatan

- Pemeliharaan berkala bersifat perbaikan
- Pemeliharaan berkala bersifat penggantian

- Perbaikan darurat akibat bencana (bencana kecil)

- Monitoring, evaluasi dan pelaporan

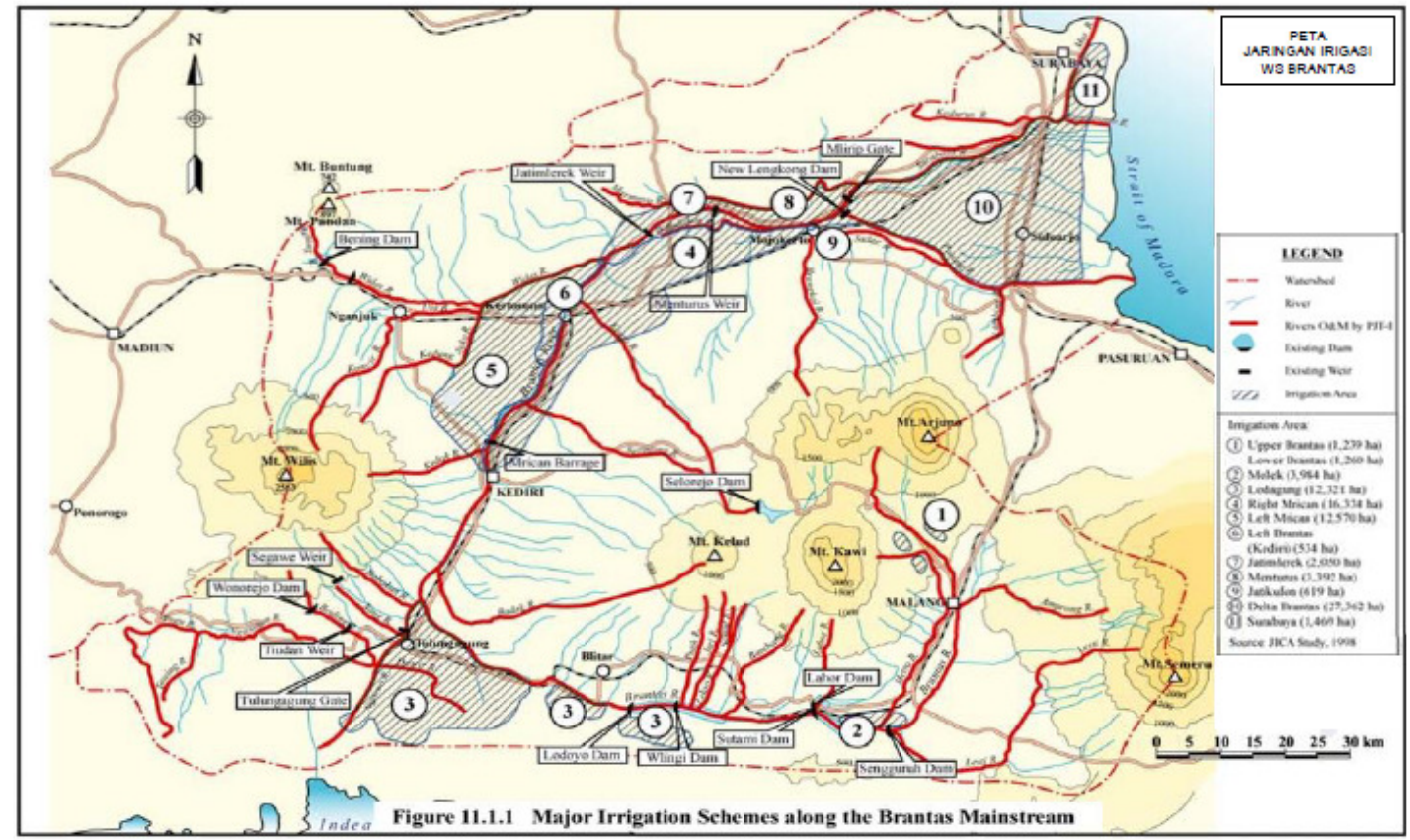

Gambar 1. Lokasi daerah studi

\section{HASIL DAN PEMBAHASAN}

\section{Dasar Penyusunan AKNOP}

Sebelum dilakukan perhitungan Angka Kebutuhan Nyata Operasi dan pemeliharaan (AKNOP) suatu daerah irigasi, perlu dilakukan penelusuran inventarisasi dan pengukuran kinerja irigasi/audit irigasi sebagai dasar dalam penentuan besarnya AKNOP (Apriadi dkk, 2019).

Kegiatan yang dilakukan dalam penelusuran inventarisasi irigasi adalah mendata seluruh sarana dan prasarana irigasi untuk mengetahui kondisi eksisting sehingga dapat diketahui tingkat kinerja irigasi. Penilaian kinerja irigasi pada saluran utama dan tersier didasarkan pada enam (6) komponen, yaitu (Kementrian PUPR, 2015):

1. Prasarana fisik

2. Produktivitas tanam

3. Kondisi operasi dan pemeliharaan

4. Petugas operasi dan pemeliharaan/organisasi personalia

5. dokumentasi

6. P3A

\section{Kelembagaan dan Organisasi Personalia}

Sumber daya manusia memiliki peranan yang penting dalam operasi dan pemeliharan irigasi.
Kecukupan personil menjadi tantangan tersediri bagi unit pelaksana teknis, karena sumber daya harus memenuhi kriteria dan persyaratan sesuai dengan peraturan pemerintah. Tabel 1 menampilkan data personil Daerah Irigasi Mrican saat ini.

Tabel 1. Sumber daya manusia operasi dan pemeliharaan Daerah Irigasi Mrican

\begin{tabular}{lcc}
\hline Petugas & ASN & THL \\
\hline Pengamat/UPTD/Ranting (orang) & 8 & \\
Staff Pengamat/UPTD/Ranting (orang) & 25 & \\
Juru/Mantri (orang) & 56 & \\
Petugas Pintu Air (orang) & 21 & 87 \\
Pekarya (orang) & 15 & 128 \\
\hline Jumlah total & 125 & 215 \\
\hline
\end{tabular}

Sumber : Dinas PUSDA Prov. Jawa timur, 2020 (data diolah)

Dengan melihat luasan daerah irigasi, jumlah pintu air, dan panjang saluran (pembawa dan pembuang), dihitung kebutuhan personil yang optimal untuk Daerah Irigasi Mrican. Karena hal ini sangat berpengaruh terhadap perhitungan biaya manajemen. Daerah Irigasi Mrican memiliki luas wilayah sebesar $30341 \mathrm{Ha}$, dengan jumlah saluran dan bangunan disajikan dalam Tabel 2 .

Berdasarkan Tabel 1 dan Tabel 2, dilakukan optimasi kebutuhan personil pada Daerah Irigasi Mrican dengan menggunakan persamaan (1) s.d (5). Hasil optimasi ditampilkan pada Tabel 3. 
Tabel 2. Panjang saluran, jumlah pintu dan jumlah bangunan

\begin{tabular}{llc}
\hline Bangunan/pintu/saluran & satuan & jumlah \\
\hline Bangunan Bagi-sadap/bagi/sadap & buah & 966 \\
Saluran pembawa primer/sekunder & $\mathrm{km}$ & 366 \\
Saluran pembuang primer/sekunder & $\mathrm{km}$ & 248 \\
Stang besar & buah & 2557 \\
Stang medium & buah & 115 \\
Stang kecil & buah & 5043 \\
\hline Sumber : Dinas PUSDA Prov. Jawa timur, 2020 (data diolah)
\end{tabular}

Tabel 3. Hasil optimasi personil operasi dan pemeliharaan DI

\begin{tabular}{lc}
\multicolumn{1}{c}{ Mrican } & \\
\hline Petugas & Hasil optimasi \\
\hline Pengamat/UPTD/Ranting (orang) & 6 \\
Staff Pengamat/UPTD/Ranting (orang) & 30 \\
Juru/Mantri (orang) & 40 \\
Petugas Pintu Air (orang) & 194 \\
Pekarya (orang) & 307 \\
Jumlah total (orang) & 577 \\
\hline
\end{tabular}

Hasil perhitungan optimasi menunjukkan bahwa terdapat kelebihan personil sebanyak 2 orang pada personil pengamat/UPTD. Hal ini akan berpengaruh terhadap jumlah staff pengamat. Staff pengamat yang ada saat ini berjumlah 25 orang. Berdasarkan hasil optimasi, jumlah staff seharusnya berjumlah 30 orang, sehingga terdapat kekurangan jumlah personil staff pengamat. Kelebihan personil juga terdapat pada juru/mantri, sebanyak 16 orang. Sedangkan kekurangan personil terdapat pada personil PPA dan pekarya masing-masing sebanyak 86 orang dan 164 orang. Kekurangan personil tersebut bisa ditambahkan dengan status tenaga harian lepas, yaitu tenaga yang diberikan honor atau upah harian sesuai dengan upah minimum regional. Jumlah personil operasi dan pemeliharaan yang ditetapkan untuk Daerah Irigasi Mrican tercantum pada Tabel 4.

Tabel 4. Penetapan jumlah personil operasi dan pemeliharaan pada Daerah Irigasi Mrican

\begin{tabular}{lc}
\hline Petugas & Hasil optimasi \\
\hline Pengamat/UPTD/Ranting (orang) & 8 \\
Staff Pengamat/UPTD/Ranting (orang) & 30 \\
Juru/Mantri (orang) & 56 \\
Petugas Pintu Air (orang) & 194 \\
Pekarya (orang) & 307 \\
\hline Jumlah total (orang) & 595 \\
\hline
\end{tabular}

Optimasi jumlah personil pada daerah irigasi mempengaruhi besaran biaya manajemen penyelenggaraan operasi dan pemeliharaan, operasi dan pemeliharaan irigasi. Komponen honor dan upah merupakan salah satu item dari biaya manajemen irigasi. Untuk personil yang berstatus Aparatur Sipil Negara, diberikan honor sebagai Tim Pelaksana Kegiatan Lapangan yang besarannya disesuaikan dengan Peraturan Menteri Keuangan No 119/PMK.02/2020 tentang Standar Biaya Masukan Tahun 2021. Beberapa item pembiayaan yang menggunakan aturan tersebut selain honor, adalah (Kementrian Keuangan, 2020): biaya perjalanan dinas, uang harian untuk perjalanan dinas, operasional kantor, pemeliharaan kendaraan operasional, konsumsi rapat, narasumber, dan akomodasi narasumber.

Sedangkan untuk tenaga harian diberikan upah sesuai dengan Keputusan Gubernur Provinsi Jawa Timur No 188/568/KPTS/013/2019 tentang Upah Minimum Kabupaten Kota di Jawa Timur. Dikarenakan Daerah Irigasi Mrican terletak pada 3 wilayah kabupaten, maka standar upah yang dijadikan acuan adalah standar upah minimum Kabupaten Jombang sebesar Rp. 2.654.095,88 dimana besaran tersebut merupakan UMK tertinggi dari ketiga wilayah kabupaten lainnya (Gubernur Jawa Timur, 2019). Besarnya upah harian adalah UMR dibagi dengan 25 hari kerja dan dialokasikan selama 12 bulan. Upah harian juga diberikan kepada tenaga operasional yang berstatus honorer dengan ketentuan sebagai berikut:

a) Kepala UPTD/pengamat $=1,3 \times$ upah kerja pekarya.

b) Staff UPTD/pengamat $=1,15 \times$ upah kerja perkarya

c) Juru/mantri $=1,2 \times$ upah kerja pekarya

d) $\mathrm{PPA} / \mathrm{POB}=1,1 \times$ upah kerja pekarya.

Besarnya biaya upah/honor pada item manajemen operasi dan pemeliharaan dapat dilihat pada Tabel 5. Sedangkan untuk tenaga honorer disajikan dalam Tabel 6.

Tabel 5. Biaya honor tim pelaksana kegiatan manajemen operasi dan pemeliharaan DI Mrican

\begin{tabular}{lcccr}
\hline \multicolumn{1}{c}{ Item } & Jumlah (orang) & Waktu (bulan) & $\begin{array}{c}\text { Biaya/bulan } \\
\text { (Rp. x 1000) }\end{array}$ & $\begin{array}{c}\text { Total } \\
\text { (Rp x 1000) }\end{array}$ \\
\hline Kepala pengamat/UPTD (ketua & 8 & 12 & 400 & 38.400. \\
Staff pengamat ( sekretaris) & 25 & 12 & 300 & 90.000. \\
Juru (Wakil ketua) & 56 & 12 & 350 & 235.200 \\
PPA (anggota) & 21 & 12 & 300 & 75.600 \\
Pekarya (anggota) & 15 & 12 & 300 & 54,000 \\
\hline & & & Total & 493.200 \\
\hline
\end{tabular}


Cantilever $\mid$ Volume: 10 Nomor: 01 April $2021 \mid$ ISSN: 1907-4247 (Print) $\mid$ ISSN: 2477-4863 (Online) $\mid$ Website: http://cantilever.id

Erna Tri Asmorowati dan Diah Sarasanty | Perencanaan Perhitungan Aknop Pada Daerah Irigasi Mrican sebagai Upaya Peningkatan Kinerja Irigasi

Tabel 6. Upah harian manajemen operasi dan pemeliharaan DI Mrican

\begin{tabular}{lccrr}
\hline Item & Jumlah (orang) & Waktu (hari) & Upah harian (Rp.) & Total (Rp. x 1000) \\
\hline Staff pengamat & 5 & 300 & 95.450 & 143.175 \\
Koordinator pengawas & 1 & 300 & 96.300 & 28.890 \\
PPA (anggota) & 173 & 300 & 91.300 & 4.738 .470 \\
\hline Total & \multicolumn{4}{r}{} \\
\hline
\end{tabular}

Dalam memperlancar kegiatan manajemen operasi dan pemeliharaan irigasi, diperlukan juga pelayanan perkantoran berupa :

- Bahan alat tulis kantor

- Prasarana kantor

- Langganan daya dan jasa

- Barang operasional lainnya berupa biaya pemeliharaan peralatan kantor misalnya servis komputer dan lain-lain.

Semua kebutuhan tersebut dihitung selama 1 tahun per unit pelaksana teknis (UPT) operasi dan pemeliharaan jaringan irigasi. Besarnya biaya operasional kantor pada DI Mrican sebesar Rp. 67.208.323,00.

Komponen berikutnya yang diperhitungkan dalam manajemen operasional dan pemeliharaan irigasi adalah sarana pelaksanaan operasi dan pemeliharaan, meliputi: kendaraan, perangkat komputer dan software, komunikasi, peralatan survei dan operasional kegiatan, serta perlengkapan kerja. Pada perhitungan komponen kendaraan, terdapat kebijakan bahwa tidak diperkenankan untuk sewa kendaraan. Anggaran AKNOP bersumber pada APBN, sehingga untuk anggaran pemeliharaan kendaraan diperkenankan jika kendaraan merupakan aset dari pemerintah pusat. Kondisi saat ini UPT tidak memiliki aset kendaraan dinas yang bersumber dari pemerintah pusat, sehingga anggaran AKNOP untuk komponen ini ditiadakan. Komponen biaya untuk manajemen pelaksanaan operasi dan pemeliharaan dapat dilihat pada Tabel 7.

Tabel 7. Biaya manajemen pelaksanaan operasional dan pemeliharaan jaringan irigasi DI Mrican

\begin{tabular}{clr}
\hline No & Parameter & Biaya (Rp. x 1000) \\
\hline 1 & Gaji/Upah/honor & $5.403 .735,00$ \\
2 & Operasional kantor & $67.208,32$ \\
3 & Sarana pelaksanaan operasi & $537.892,15$ \\
& $\begin{array}{l}\text { dan pemeliharaan } \\
4\end{array}$ & $\begin{array}{l}\text { Kegiatan pendukung } \\
\text { operasi dan pemeliharaan }\end{array}$ \\
\hline \multicolumn{2}{r}{ Total } & $320.931,76$ \\
\hline
\end{tabular}

Kegiatan operasi irigasi permukaan merupakan kegiatan yang berupaya untuk mengatur air irigasi dan drainasenya. Kegiatan yang termasuk dalam kegiatan ini adalah pengaturan pintu air, perencanaan pola tata tanam, penyusunan sistem golongan, penyusunan rencana pembagian air, pelaksanaan kalibrasi bangunan ukur/pintu, pelaksanaan pengumpulan data, serta pemantauan dan evaluasi. Pada daerah tertentu, keberadaan air irigasi tidak tersedia secara terus-menerus, sehingga dibutuhkan pemanfaatan sumber lain yang berasal dari air tanah atau pemanfaatan kembali air drainase. Sehingga, kegiatan operasional irigasi permukaan harus memasukkan komponen tersebut dalam pembiayaannya. Perhitungan biaya penggunaan sumber lain terdiri dari biaya operasional pompa air yang ada dan bahan bakar yang digunakan selama operasional. Dalam operasional pompa, perhitungan bahan bakar dihitung selama 6 bulan dengan volume 12 liter/bln. Besaran biaya operasi irigasi permukaan pada Daerah Irigasi Mrican dapat dilihat pada Tabel 8.

Tabel 8. Biaya operasional irigasi permukaan DI Mrican

\begin{tabular}{clr}
\hline No & Parameter & Biaya (Rp) $\times 1000$ \\
\hline 1 & Perencanaan operasi & $219.877,16$ \\
2 & Pelaksanaan operasi & $31.173 .324,00$ \\
3 & Pemanfaatan sumber lain & $1.145,66$ \\
4 & Monitoring dan evaluasi & $95.861,90$ \\
\hline \multicolumn{2}{l}{ Total } & $31.490 .208,72$ \\
\hline
\end{tabular}

Kegiatan pemeliharaan jaringan irigasi diperlukan untuk memperlancar pelaksanaan operasi jaringan irigasi dan mempertahankan fungsi saluran dan bangunan irigasi. Berdasarkan Peraturan Menteri PUPR No 12/PRT/M/2015 tentang Eksploitasi dan Pemeliharaan Jaringan Irigasi, ruang lingkup pemeliharan meliputi: inventarisasi kondisi jaringan irigasi, perencanaan, pelaksanaan, pemantauan dan evaluasi. Kegiatan pemeliharan jaringan irigasi meliputi: kegiatan pengamanan, pemeliharaan rutin, pemeliharaan berkala, dan perbaikan darurat.

Pelaksanaan pekerjaan pemeliharaan pada jaringan terdiri dari dua macam, yaitu bersifat swakelola dan bersifat kontraktual. Pekerjaan yang bersifat swakelola dikerjakan oleh petugas operasi dan pemeliharaan bersama-sama dengan masyrakat, dalam hal ini petani yang tergabung dalam P3A (Perkumpulan Petani Pemakai Air). Petugas operasi dan pemeliharaan yang bertugas secara langsung dalam pelaksanaan pemeliharaan adalah:

1) Juru yang bertugas dalam pemeliharaan rutin bersifat perbaikan sebanyak 56 orang. 
2) Petugas Pintu Air (PPA) untuk kegiatan perawatan pintu air, membersihkan sampah dan endapan pada bangunan bagi/sadap/bagi-sadap yang berada disekitar bangunan ukur. Pada DI Mrican berjumlah 194 orang.

3) Pekarya untuk kegiatan membersihkan saluran dan bangunan dari tanaman liar dan semaksemak, membersihkan endapan lumpur yang berada disaluran serta memelihara tanaman lindung di sekitar bangunan tepi luar tanggul saluran. Jumlah pekarya yang berstatus tenaga harian lepas berjumlah 292 orang.

Dari hasil inventarisasi kondisi jaringan irigasi pada Daerah Irigasi Mrican terdapat beberapa saluran sekunder dan bangunan yang memerlukan biaya perbaikan berkala bersifat perbaikan dengan cara kontraktual pihak ketiga (Tabel 9).

Tabel 9. Kegiatan pemeliharaan berkala bersifat perbaikan dengan cara kontraktual pada DI Mrican

\begin{tabular}{llrr}
\hline Nama saluran dan bangunan & Lokasi & Jumlah & Biaya (Rp. Juta) \\
\hline Turi Baru dan BPP. 36 & Kec. Megaluh Kab.Jombang & $215 \mathrm{~km}$ & 400 \\
B.1 & Kec. Prambon Kab. Nganjuk & $235 \mathrm{~km}$ & 400 \\
B.4 & Kec.Prambon, Kab.Nganjuk & $255 \mathrm{~km}$ & 195 \\
B.25 & Kec.Tanjunganom, Kab.Nganjuk & $124 \mathrm{~km}$ & 192 \\
B.24 & Kec.Tanjunganom, Kab.Nganjuk & $127 \mathrm{~km}$ & 192. \\
Pilanghilir, & Kec.Bandar Kedungmulyo, Kab.Jombang, & $128 \mathrm{~km}$ & 195 \\
Melik & Kec.Tembelang, Kab.Jombang & $122 \mathrm{~km}$ & 196,8 \\
Pemeliharaan pintu - pintu & Kec.Purwoasri, Kab.Kediri & $4 \mathrm{bh}$ & 165 \\
air, Bang. BGR.3 & & $135 \mathrm{~km}$ & 192 \\
Ketawang, & Kec.Purwoasri, Kab.Kediri & & $2.127,8$ \\
\hline Total & &
\end{tabular}

Dalam kegiatan pemeliharaan DI Mrican, terdapat kegiatan pemeliharaan berkala bersifat penggantian, yaitu :

- Penggantian patok batas aset sebanyak $12280 \mathrm{bh}$.

- Penggantian nomenklatur sebanyak 1501 buah

- Penggantian papan eksploitasi sebanyak 733 buah.

Hal tersebut dilakukan karena kondisi saat ini banyak sekali patok batas aset yang hilang, serta nomenklatur dan papan eksploitasi yang rusak. Pemasangan patok batas aset berada di kanan dan kiri saluran setiap $100 \mathrm{~m}$. Sedangkan penggantian papan eksploitasi disesuaikan dengan jumlah saluran yang ada pada daerah irigasi.

Kegiatan monitoring dan evaluasi pada pemeliharaan jaringan irigasi permukaan, meliputi:

- Bahan

- Konsumsi rapat

- Supervisi dari balai/provinsi

Kebutuhan anggaran untuk pelaksanaan pemeliharaan jaringan irigasi permukaan pada Daerah Irigasi Mrican untuk tahun anggaran 2021 dapat dilihat pada Tabel 10.

Tabel 10. Biaya Pemeliharaan Irigasi Permukaan Daerah Irigasi Mrican

\begin{tabular}{llr}
\hline No & Parameter & Biaya (rp) x 1000 \\
\hline 1 & Perencanaan pemeliharaan & $368.761,45$ \\
2 & Pelaksanaan pemeliharaan & $22.293 .234,92$ \\
3 & Monitoring dan evaluasi & $23.848,00$ \\
\hline & & Total \\
\hline
\end{tabular}

Total biaya Angka Kebutuhan Nyata Operasi dan Pemeliharaan (AKNOP) tahun anggaran 2021 untuk
Daerah Irigasi Mrican sebesar Rp. 60.505.820.327,00 dengan rincian sebagai berikut:

1) Biaya pelaksanaan operasi dan pemeliharaan $\mathrm{Rp}$. 6.329.767,23 atau 10,5\% dari biaya AKNOP total.

2) Operasi irigasi permukaan $\mathrm{Rp}$. 31.490.208.724,00 atau sebesar 52\%. Parameter biaya paling besar berasal dari pengoperasian bangunan bagi/bagi sadap/sadap sebanyak 966 buah bangunan dikerjakan oleh 194 orang PPA sebanyak dua kali dalam setahun dengan upah harian sebesar Rp. 83.000,00. Besaran parameter ini sebesar Rp. 31.109.064.000,00

3) Pemeliharaan irigasi permukaan $\mathrm{Rp}$ 22.685.844.371,00 atau 37,5\% .

Besarnya prosentase komponen biaya pada AKNOP tergantung dari kondisi masing-masing daerah irigasi, tidak ada ketentuan pasti besarnya prosentase tersebut.

\section{KESIMPULAN}

Dari hasil perhitungan dan analisa yang telah dilakukan, didapatkan Angka Kebutuhan Nyata Operasi dan Pemeliharaan (AKNOP) DI Mrican untuk komponen manajemen operasional irigasi sebesar Rp. 6.329.767,23. Untuk komponen biaya operasi irigasi permukaan memerlukan biaya sebesar Rp. 31.490.208.724,00. Sedangkan untuk komponen pemeliharaan jaringan irigasi permukaan sebesar Rp 22.685.844.371,00. Sehingga, total biaya AKNOP DI Mrican sebesar Rp. 60.505.820.327,00 
Cantilever | Volume: 10 Nomor: 01 April 2021 | ISSN: 1907-4247 (Print) $\mid$ ISSN: 2477-4863 (Online) $\mid$ Website: http://cantilever.id

Erna Tri Asmorowati dan Diah Sarasanty | Perencanaan Perhitungan Aknop Pada Daerah Irigasi Mrican sebagai Upaya Peningkatan Kinerja Irigasi

\section{REFERENSI}

Djuhartono, A. (2020). Petunjuk Teknis Tata Cara Penyusunan Angka Kebutuhan Nyata Operasi Dan Pemeliharaan (Aknop) Jaringan Irigasi.

birohukum.pu.go.id/uploads/DPU/2015/PermenPUPR232015.pdf

Pemerintah Provinsi Jawa Timur (2019). Keputusan Gubernur Jawa Timur Nomor 188/568/KPTS/013/2019 tentang Upah Minimum Kabupaten/Kota di Jawa Timur Tahun 2020.

Kementrian Keuangan (2020). Peraturan Menteri Keuangan Republik Indonesia Nomor 119/PMK.02/2020 Tentang Standar Biaya Masukan Tahun Anggaran 2021.

Kementrian PUPR (2015). Peraturan Menteri Pekerjaan Umum dan Perumahan Rakyat Republik Indonesia Nomor 14/PRT/M/2015 tentang Kriteria dan Penetapan Status

\section{Daerah Irigasi.}

Puspitasari, I. (2014). Model Alokasi Pendanaan Pemeliharaan Infrastruktur Irigasi Dengan Metode AHP (Analytic Hierarcy Process). Ejournal.Poltektedc.Ac.Id, 8(2), 160 170.

Apriadi R., Sumiadi, Sisinggih, D. (2019). Audit Teknis Sebagai Dasar Penyusunan Aknop Pada Wetan Kabupaten Malang. Jurnal Mahasiswa Jurusan Teknik Pengairan, 2(2).

http://pengairan.studentjournal.ub.ac.id/index.php/jmtp/ar ticle/view/399

Soekrasno, S. (2019). Penyempurnaan Sistem Pengelolaan Air Irigasi Menghadapi Irigasi Modern Di Indonesia. Indonesian Journal of Construction Engineering and Sustainable Development (Cesd), 1(2), 67. https://doi.org/10.25105/cesd.v1i2.4103 